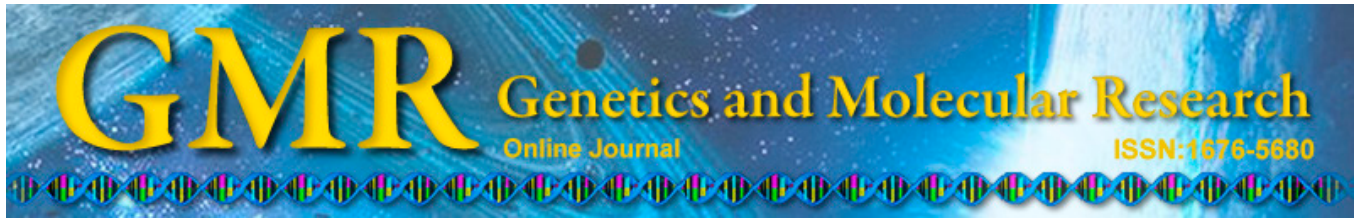

\title{
Expression of $L T P$ genes in response to saline stress in rice seedlings
}

\author{
G.P. Moraes ${ }^{1}$, L.C. Benitez ${ }^{1}$, M.N. do Amaral ${ }^{1}$, I.L. Vighi ${ }^{1}$, \\ P.A. Auler ${ }^{1}$, L.C da Maia $^{2}$, V.J. Bianchi ${ }^{1}$ and E.J.B. Braga ${ }^{1}$ \\ ${ }^{1}$ Departamento de Botânica, Universidade Federal de Pelotas, \\ Pelotas, RS, Brasil \\ ${ }^{2}$ Departamento de Fitotecnia, Universidade Federal de Pelotas, \\ Pelotas, RS, Brasil \\ Corresponding author: G.P. Moraes \\ E-mail: gabriela.moraes.freitas@gmail.com
}

Genet. Mol. Res. 14 (3): 8294-8305 (2015)

Received October 1, 2014

Accepted February 20, 2015

Published July 27, 2015

DOI http://dx.doi.org/10.4238/2015.July.27.18

\begin{abstract}
Saline stress is one of the primary factors limiting increased rice productivity in the southern region of Brazil. Farming can be affected by salinity that is due to both the origin of the soils as well as the irrigation water. Lipid transfer proteins (LTPs) have many physiological functions, including in the response to saline stress. Therefore, the objective of this study was to quantify the relative expression of 11 genetic isoforms that encode LTP1-type proteins in rice genotypes tolerant and sensitive to saline stress in the vegetative period. When the plants reached development stage V4, alternating irrigation was started with nutritive solution and water containing $150 \mathrm{mM} \mathrm{NaCl}$. The LTP7 gene showed an increase in expression by 13.81-fold after $96 \mathrm{~h}$ of stress exposure in the saline-tolerant group, whereas the LTP10 gene expression level was increased by 71.10 fold after $96 \mathrm{~h}$ in the saline-sensitive group. The LTP26, LTP23, and LTP 18 genes showed increased expression in both genotypes; however, the expression levels and response times were different. Thus, LTP7 and LTP10 showed the highest response to salinity. The
\end{abstract}


LTP18, LTP23, and LTP26 genes were negatively correlated with the response to salinity.

Key words: Abiotic stress; Lipid transfer proteins; Oryza sativa L.; $U B Q 10$

\section{INTRODUCTION}

Rice (Oryza sativa L.) is one of the most important cereals worldwide and is cultivated and consumed on all continents, indicating its social and economic importance (FAO, 2013). Despite the good productivity levels achieved, enhanced variation over time caused by changing climatic conditions has been observed.

Saline stress, caused primarily by the accumulation of $\mathrm{NaCl}$, is a problem for agriculture worldwide and is most severe in arid and semiarid regions, where elevated rates of evapotranspiration and low rainfalls associated with inadequate soil and water management contribute to the emergence of saline soils (Zhu, 2001). According to data from the Food and Agriculture Organization of the United Nations (FAO, 2008), approximately $20 \%$ of cultivated lands in the world are facing salinization problems.

The tolerance levels of rice to saline stress vary according to the developmental stage of the culture. The seedling and reproduction periods are the most critical for the salinity of the irrigation water; the highest tolerance level occurs during germination (Djanaguiraman et al., 2003).

An increase in the production of reactive oxygen species and changes in the concentrations of total soluble carbohydrates, total phenols, betaine glycine, proline, chlorophyll, and proteins are among the primary damaging events caused by saline stress. At the cellular level, salinity causes disturbances in the plasma membrane, with its effects manifested by alterations in the permeability, lipid composition, electrical potential, and activity of enzymes and proteins connected to the membrane (Mittler, 2002; Mansour et al., 2003; Panda and Khan, 2009).

Lipid transfer proteins (LTPs) comprise a family known as the alpha-amylase inhibitors, lipid transfer (LT), and seed storage family. LTPs are small proteins of approximately 10 $\mathrm{kDa}$ and are abundantly present in higher plants. Biochemically, LTPs are subdivided into 2 distinct families (LTP1 and LTP2), which can bind to fatty acids and transfer phospholipids between membranes. Although both families are characterized by an elevated isoelectric point ( 9) and a conserved motif of 8 cysteine residues (C... C. .. CC ... CXC ... C. .. C), LTP1 and LTP2 differ in weight and show low similarity ( $\sim 30 \%$ identity) between their amino acid sequences. The two families also share a common structural architecture formed by a hydrophobic cavity closed by an $\alpha$-helix (Yeats and Rose, 2007).

Early studies suggested that LTPs were related only to the transfer and binding of fatty acids and phospholipids between membranes; however, these proteins have subsequently been shown to be involved in lipid composition modification and membrane biogenesis (Wu et al., 2004; Kirubakaran et al., 2008; Yi et al., 2009). In addition, LTPs show antifungal activity and play a vital role in the defense response of plants to attacks from pathogens (Gomes et al., 2003).

An important function attributed to the LTPs is their involvement in responses to different abiotic stresses (Jang et al., 2002). Genes encoding LTP proteins are differentially regulated under various environmental conditions such as elevated temperature (Oshino et al., 2007), cold stress (Hwang et al., 2005), saline stress (Vignols et al., 1997; Liu and Lin, 2003; Wu et al., 2004; Gonorazky et al., 2005; Choi et al., 2008), and stress due to heavy metals 
(Hollenbach et al., 1997). Treatment with abscisic acid (ABA) can also induce the differential expression of the LTP genes (Yubero-Serrano et al., 2003; Federico et al., 2005).

Studies have examined the physiological role of LTP proteins (Carvalho and Gomes, 2007 ) to identify genetic isoforms through alignments in the data bank for phylogenetic analyses of different species (Boutrot et al., 2008; Wang et al., 2012) and to describe the structure of these proteins (Pacios et al., 2012). However, functional studies are also important for determining the differential expression of these genes using specific expression techniques such as real-time quantitative-polymerase chain reaction (RT-qPCR).

Thus, the objective of this study was to evaluate the differential expression of 11 genes encoding members of the LTP1 protein family in rice cultivars tolerant and sensitive to saline stress in order to identify genetic isoforms that are potentially responsive to this environmental condition.

\section{MATERIAL AND METHODS}

\section{In silico identification of $L T P 1$ genes of rice}

To search for possible LTP genes, the information contained in the Phytozome v.9.1 databank of genetic families was used, selecting only the sequences of proteins annotated with the HMMPfam PF00234 domain (plant lipid transfer/seed storage/trypsin-alpha amylase inhibitor). Using information from the locus name, the ID number (OsXg....), and sequences of amino acids encoded by each of the possible sequences of LTP genes, we detected transcription using the ID converter tool available in the rice databank RAP-DB.

The amino acid sequences were then aligned in the Conserved Domains and Protein Classification bank deposited in the National Center for Biotechnology Information to verify whether the sequences contained the conserved motif of 8 cysteine residues (C. . C . . CC ... CXC ... C. .. C). Alignments with a statistical e-value $\leq \mathrm{e}^{-10}$ and identification code [cd01960], which are characteristic of LTP1 proteins, were considered to be significant.

Furthermore, ProtParam tools (http://web.expasy.org/protparam) were used to analyze the physical-chemical parameters, and WoLF PSORT was used to predict the subcellular localization of LTP proteins.

The location of each LTP1 gene on the chromosome was determined using information from annotations contained in the RAP-DB.

\section{Expression profile of $L T P 1$ genes}

\section{Analysis of expression based on experimental data}

Rice seeds (O. sativa L.) from the BRS Bojuru (tolerant to salt) and BRS Ligeirinho (sensitive to salt) genotypes were disinfected with $1 \%$ hypochlorite for $24 \mathrm{~h}$ and incubated in a biological oxygen demand Eletrolab EL202 incubator (São Paulo, Brazil) with a 12-h photoperiod at $25^{\circ} \pm 2{ }^{\circ} \mathrm{C}$ for 10 days. After this period, the seedlings were transferred to $500-\mathrm{mL}$ plastic pots containing sand as a substrate in a greenhouse and irrigated, alternating every 2 days with water and a Hoagland and Arnon (1938) nutritive solution.

When the plants reached the $\mathrm{V}_{4}$ development stage, they were subjected to alternating irrigation with a nutritive solution and water containing $150 \mathrm{mM} \mathrm{NaCl}$, including $100 \mathrm{~mL} /$ pot. 
The $\mathrm{NaCl}$ concentration was chosen based on data from the literature for experiments with saline stress in rice (Hong et al., 2007; Karan et al., 2012; Abbas et al., 2013).

The collection of leaves for analyses was performed in the morning at 24-h intervals and designated as $\mathrm{C} 1, \mathrm{C} 2, \mathrm{C} 3, \mathrm{C} 4$, and $\mathrm{C} 5$, where $\mathrm{C} 1$ were plants not exposed to stress (control); $\mathrm{C} 2, \mathrm{C} 3, \mathrm{C} 4$, and $\mathrm{C} 5$ were exposed to $24,48,72$, and $96 \mathrm{~h}$ of stress, respectively. The experimental design was entirely random, in a 2 x 5 factorial scheme ( 2 genotypes x 5 collections), and 3 biological repetitions were conducted, with each repetition comprising 3 pots containing 5 plants each.

\section{Total RNA extraction and synthesis of cDNA}

Total RNA was extracted from $100 \mathrm{mg}$ leaves, according to the method described for the Plant RNA Reagent Purelink ${ }^{\circledR}$ reagent (Invitrogen, Carlsbad, CA, USA). The quantity and purity of RNA were measured using a NanoDrop ND-1000 spectrometer (GE Healthcare, Little Chalfont, UK), while the quality and integrity of the RNA were verified using gel electrophoresis on a $1.0 \%$ agarose gel. Single-stranded cDNAs were synthesized by reverse transcription from $2 \mu \mathrm{g}$ total RNA using the oligoDT primer and a SuperScript First-Strand Synthesis System for reverse transcription-PCR (Invitrogen).

\section{Primer design and efficiency}

Based on the nucleotide sequences of the transcripts, the primers were designed using the Primer Express v.3.0 (Applied Biosystems, Foster City, CA, USA), BioEdit v.7.0 (http://www. mbio.ncsu.edu/bioedit/bioedit.html), and PerlPrimer v.1.1.21 (http://perlprimer.sourceforge.net/) software programs. Primers were selected with annealing temperatures from $58^{\circ}$ to $60^{\circ} \mathrm{C}$ and amplicon sizes from 50 to 150 base pairs, designed towards the $3^{\prime}$ end, with the absence of dimer formation, cross-dimers, and hairpins. Prior to primer design, alignments were performed between the possible isoforms of the selected $L T P$ s to guarantee the specificity of each primer set.

The specificity and standard efficiency curve of the primers were evaluated for each genotype, and the average efficiency was later calculated between both genotypes. Initially, the specificity of each primer set was verified based on the melting curve, and only primers with specific amplicons, which were those showing a single dissociation peak of the strands for the PCR products, were retained.

PCR efficiency was obtained from 4 serial dilutions of cDNA $(1: 1 ; 1: 5,1: 25$, and 1:125) to generate a standard curve for each primer pair tested. The value of PCR efficiency was calculated according to the equation of Rasmussen (2001), with efficiency values between 1.8 and 2.2 considered acceptable and corresponding to a reaction efficiency of $90-110 \%$. The reactions were performed in triplicate for each cDNA dilution. The primers used in this study are listed in Table 1.

\section{Relative quantification}

The total volume of the real-time qPCR was $12.0 \mu \mathrm{L}$, containing $6.25 \mu \mathrm{L}$ SYBR Green fluorophore (Applied Biosystems), $0.25 \mu \mathrm{L} 10 \mathrm{mM}$ of each primer (forward and reverse), 1.0 $\mu \mathrm{L}$ cDNA (1:25 dilution, as previously defined), and $4.25 \mu \mathrm{L}$ ultra-pure water. The reactions were performed in a Bio-Rad CFX Real-Time Thermocycler (Hercules, CA, USA) using the following amplification parameters: $95^{\circ} \mathrm{C}$ for $10 \mathrm{~min}, 40$ cycles of $95^{\circ} \mathrm{C}$ for $15 \mathrm{~s}, 60^{\circ} \mathrm{C}$ for 1 
min with insertion of the melting curve from 65 to $95^{\circ} \mathrm{C}$, and $72^{\circ} \mathrm{C}$ for 10 min with an increase of $5^{\circ} \mathrm{C}$ with each measure of fluorescence. Three technical repetitions were performed (triplicate) for each biological repetition.

\begin{tabular}{|c|c|c|c|}
\hline Gene & Forward primer $\left(5^{\prime}-3^{\prime}\right)$ & Reverse primer $\left(5^{\prime}-3^{\prime}\right)$ & Efficiency \\
\hline LTP7 & GGAGGGTGTGACATCGCAGG & AAGCGTGAGACGACGACAGGT & 2.08 \\
\hline LTP8 & ССТСТАСТСССТСТАТСССА & CGAACATAAGACTGGATGTGAC & 2.08 \\
\hline LTP10 & ATTAACCAACACCGAGCATCA & CGATCGATCCAGAGGATGCTA & 2.09 \\
\hline LTP12 & CCATCCATCATCCATCTCATCATC & GCTAGTACTGTTGATCTAGTTGCTG & 1.87 \\
\hline LTP13 & СTTCTTGTTGCTGAGGCAATCTG & TTATGGGACGGAGGGAGTAGAG & 2.07 \\
\hline LTP14 & TCTAGCTTAGCTACTCGATCATCAG & CAAGATTACTGATTTGATCGTCGGA & 2.03 \\
\hline LTP17 & TGGAAGCAGCACTTTCGGC & TTATTCATTCACGGCCCACG & 1.85 \\
\hline LTP18 & TACCCATCCTTGCAGCTCACG & CATCGTCTCCATCAGGGCCA & 2.16 \\
\hline LTP23 & TTTGATCTGTCTCCTTTACGGGAC & AAGATTCATGCATGATTCGTCTGC & 1.95 \\
\hline LTP25 & CTTGCTGCATGCGTACGT & GTACGCATGTATCAGTACGAC & 1.98 \\
\hline LTP26 & CATGCGTACGTGCACTATAT & CATGTAAACATTGAAACGCAT & 2.10 \\
\hline
\end{tabular}

The relative quantification of expression (RQ) was calculated using the comparative threshold cycle method (Livak and Schmittgen 2001), using the equation RQ $=2^{-\Delta \Delta C t}$. Based on the RQ values, analysis of variance (proc glm) was used to test possible variations for the salt exposure times and genotype in an isolated manner, as well as their interaction, with values of $\mathrm{P} \leq 0.05$ considered significant. The analyses were performed using SAS Algorithm v.9.3 software (SAS Institute Inc., Cary, NC, USA).

The ubiquitin10 gene (AK101547) was selected as an internal reaction standard according to Moraes et al. (2015). It was previously selected from 9 other standard candidates (Actin11, Ubiquitin-E2, Eukaryotic elongation factor 1 $\alpha$, Glyceraldehyde-3-phosphate dehydrogenase, $\beta$-tubulin, Eukaryotic initiation factor 4a, Ubiquitin5, Aquaporin Tip41, and Cyclophilin), tested using the same experimental samples used in this study.

\section{Similarity and heatmap of $L T P 1$ gene expression}

The similarity, grouping, and heatmap analyses were performed based on the RQ values. The Euclidean distance was used to calculate similarity, the unweighted pair group method with arithmetic mean was used for grouping, and the proc sgrender procedure was used for the heatmap using the SAS v.9.3 software.

\section{Correlation analysis of $L T P 1$ gene expression}

To measure the strength of the correlation of expression between the LTP genes, the Pearson correlation coefficient was calculated and was represented graphically using a heatmap. The analyses were performed using the SAS v.9.3 software, using the proc corr and proc sgrender procedures.

\section{RESULTS}

Based on the search performed of the Phytozome databank, 158 genes described as 
LTPs were identified; however, only 14 genes met the selection criteria and were selected for analysis (Figure 1, Table 2).

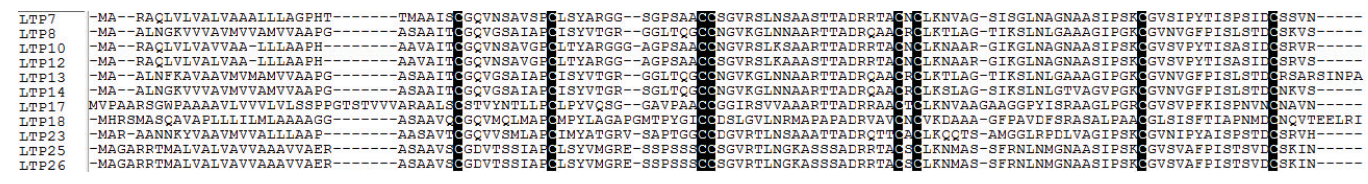

Figure 1. Alignment of the amino acid sequences of the LTP proteins from rice (Oryza sativa L.), highlighting the conserved cysteine residues. Multiple alignment was performed using ClustalW.

Table 2. Specifications of LTP1 proteins, with their respective accession Nos. (Phytozome), names (RAPDB), transcript codes, e-values (CDD), physical-chemical characteristics, subcellular localizations (PSORT Predictions), and locations on the chromosome.

\begin{tabular}{llllllllll}
\hline Accession & Name & Transcript & e-value & AA & Weight & pI & Atoms & Subcellular localization & Location on the chromosome \\
\hline LTP7 & Os11g0115350 & AK058896.1 & $4.77 \mathrm{e}^{-16}$ & 118 & 11.50 & 8.93 & 1604 & E:11; V: 2 & chr11:693326..694254 \\
LTP8 & Os11g0116000 & AK061182.1 & $1.56 \mathrm{e}^{-28}$ & 118 & 11.44 & 9.38 & 1620 & E:11; Ch:1; C:1 & chr11:715445..716478 \\
LTP10 & Os11g0427800 & AK061288.1 & $1.30 \mathrm{e}^{-24}$ & 117 & 11.56 & 9.93 & 1635 & E:13 & chr11:13668526..13669487 \\
LTP12 & Os12g0115100 & CU406598.1 & $1.15 \mathrm{e}^{-14}$ & 116 & 11.34 & 9.58 & 1603 & E:11; V: 2 & chr12:737314..738254 \\
LTP13 & Os12g0115300 & AK059737.1 & $1.55 \mathrm{e}^{-28}$ & 123 & 12.05 & 9.58 & 1698 & E:11; Ch:1; C:1 & chr12:746162..747120 \\
LTP14 & Os12g0115500 & AK241677.1 & $1.02 \mathrm{e}^{-27}$ & 118 & 11.51 & 9.38 & 1628 & E:12; Ch:1 & chr12:760947..762381 \\
LTP17 & Os05g0477900 & AK243196.1 & $1.56 \mathrm{e}^{-14}$ & 129 & 12.66 & 9.63 & 1794 & Ch:12; E: 2 & chr05:23508215..23509009 \\
LTP18 & Os01g0219500 & AK109524.1 & $4.16 \mathrm{e}^{-23}$ & 127 & 12.91 & 5.55 & 1797 & Ch:13 & chr01:6541008..6543076 \\
LTP23 & Os12g0114500 & AK073466.1 & $3.58 \mathrm{e}^{-29}$ & 150 & 17.54 & 11.63 & 2479 & N: 7, C: 3; Ch:1; M:1; E.R.:1 chr12:723297..724220 \\
LTP25 & Os11g0115100 & AK119692.1 & $2.94 \mathrm{e}^{-22}$ & 121 & 12.14 & 9.27 & 1686 & E: 8; Ch: 6 & chr11:684777..685551 \\
LTP26 & Os12g0114800 & AK104005.1 & $2.94 \mathrm{e}^{-22}$ & 121 & 12.14 & 9.27 & 1686 & E: 8; Ch: 6 & chr12:727802..728559 \\
\hline
\end{tabular}

E(extracellular); V (vacuolar); C (cytosol); Ch(chloroplast); N (nuclear); E.R. (endoplasmic reticulum); M(mitochondria).

\section{Expression analysis}

In the analysis of amplification specificity, the melting curves showed that the selected primers had single, very well-defined peaks, confirming the specificity of the amplified product with efficiencies varying from 1.8 to 2.2 (Figure S1).

A significant effect was observed for the interaction between genotype and collection factors for all evaluated genes. The LTP8, LTP12, and LTP13 genes showed the lowest variations in the RQ as a function of time of exposure to stress. The LTP12 and LTP13 genes were fit to the cubic equations for both genotypes. For BRS Bojuru, the highest expression levels were observed between the 48- and 72-h time periods for LTP12 and at $24 \mathrm{~h}$ for LTP13, indicating that these genetic isoforms were the least responsive to salinity (Figure 2A, B and C).

A quadratic response was observed for the RQ of the LTP7 gene, with increases found in the expression levels at $96 \mathrm{~h}$ of exposure to stress; however, this increase was more accentuated in BRS Bojuru, at 13.8-fold higher than the control (Figure 2D).

The LTP14 gene was fit to a cubic equation for both genotypes, with an increase up to $72 \mathrm{~h}$, followed by a decrease. The LTP25 and LTP 10 genes showed the most contrasting responses between genotypes. In BRS Bojuru, a quadratic regression curve was fit to LTP25, while a cubic curve was fit to LTP10, with an increase in the transcript levels up to $72 \mathrm{~h}$. For BRS Ligeirinho, similar values to the control were observed until $72 \mathrm{~h}$ of stress exposure, which was 23.28-fold higher than the control levels of the LTP25 gene after this period; there 
was an increase in the expression level of the LTP10 gene over the 48-h exposure to stress, reaching 71.10-fold higher than the normal level in the 96-h time period (Figure 2E, F, G).
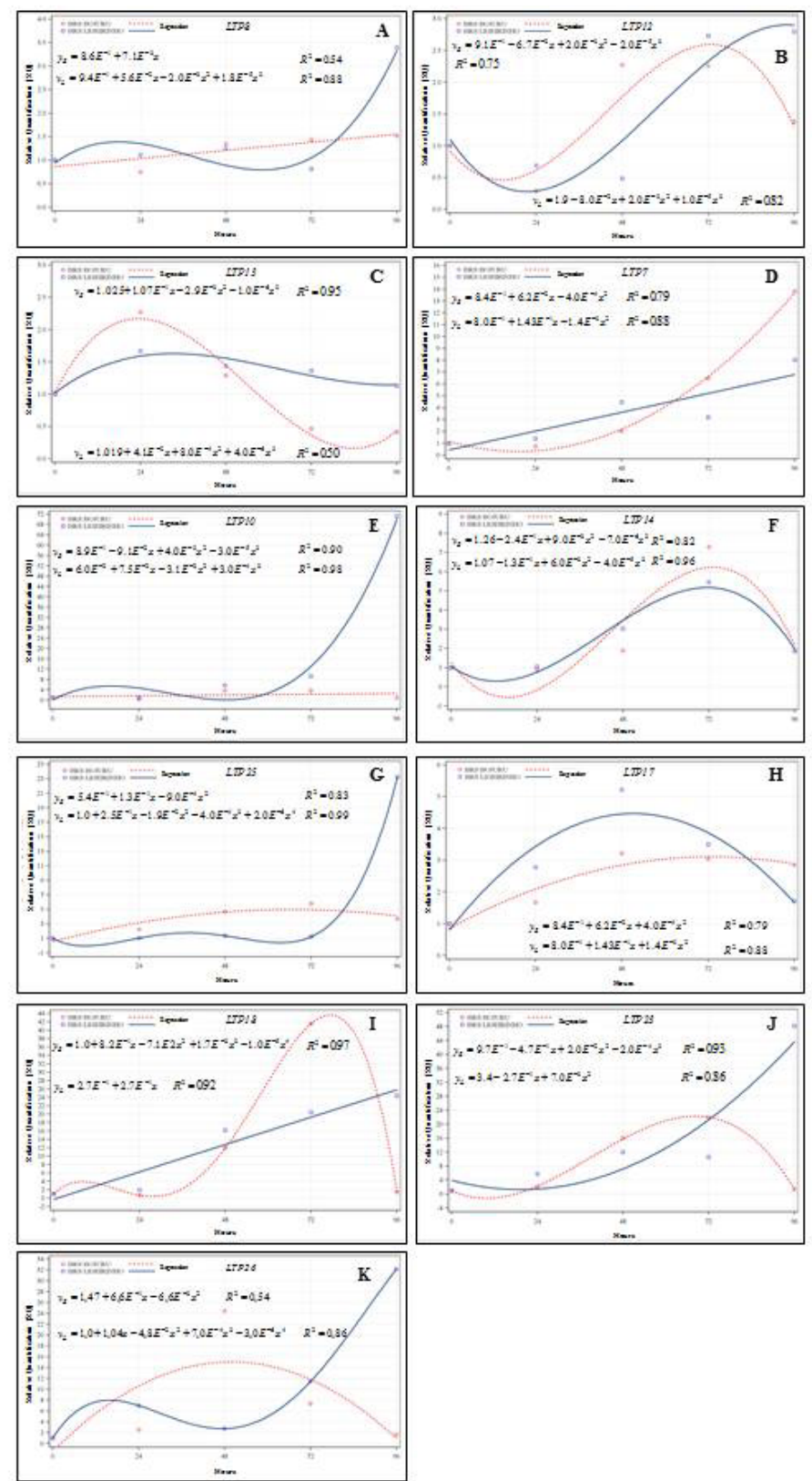

Figure 2. Relative quantification of expression (RQ) of the $L T P$ genes in rice genotypes subjected to saline stress. $\mathbf{A}=L T P 8, \mathbf{B}=L T P 12, \mathbf{C}=L T P 13, \mathbf{D}=L T P 7, \mathbf{E}=L T P 10, \mathbf{F}=L T P 14, \mathbf{G}=L T P 25, \mathbf{H}=L T P 17, \mathbf{I}=L T P 18, \mathbf{J}=$ $L T P 23$ and $\mathbf{K}=L T P 26$. 
Regression analysis for the LTP 17 gene revealed a quadratic response for the 2 genotypes, with the highest expression values found at $48 \mathrm{~h}$ of saline stress (Figure $2 \mathrm{H}$ ). The LTP18, LTP26, and LTP23 genes were among the most responsive to $\mathrm{NaCl}$ treatment. Significant increases in expression were observed over the time of exposure to salinity for the 2 genotypes (Figure 2I, K and J); however, the increases occurred at different levels and times. In the saline-sensitive genotype (BRS Ligeirinho), all genes showed increased expression up to $96 \mathrm{~h}$, as well as the genes $L T P 10$ and $L T P 25$ with RQ values of 71.1 and 23.26, respectively, while for BRS Bojuru, the highest RQ values were observed between 48 and $72 \mathrm{~h}$, with decreased expression observed at $96 \mathrm{~h}$ reaching values close to the control treatment (Figure 2A and G).

Evaluation of the Pearson correlation data revealed 7 sequences with positive correlations (LTP7, LTP 8, LTP12, LTP13, LTP14, LTP18, and LTP17) between genotypes, representing the $L T P$ s with the most similar response between the 2 genotypes. LTP14 expression was shown to be strongly positively correlated between groups, indicating a similar response in the expression of this gene between genotypes. LTP25 expression was not correlated between genotypes (Figure 3).

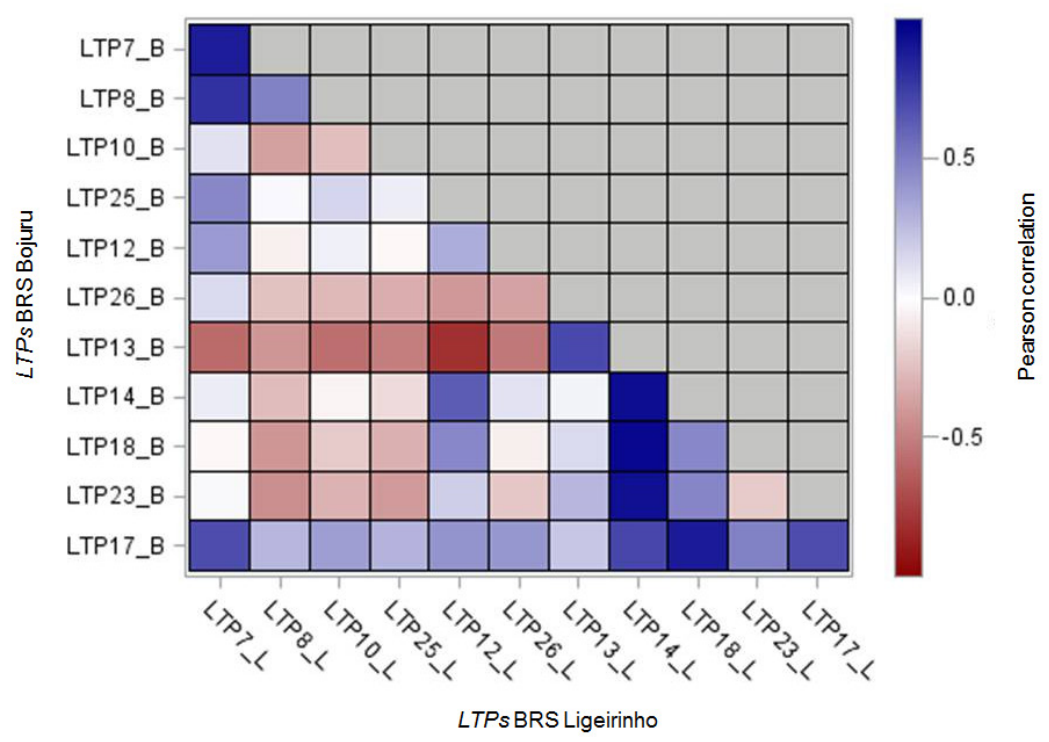

Figure 3. Correlation between the relative expression of LTP genes in response to saline stress and contrasting rice genotypes, BRS Bojuru (saline-tolerant) and BRS Ligeirinho (saline-sensitive), represented graphically using a heatmap.

Based on grouping analysis, the LTP18, LTP23, and LTP26 genes were more responsive to salt stress for both genotypes, but this response occurred at different times. For BRS Ligeirinho, higher expression of the LTP10 (71.1) and LTP25 (23.26) genes were observed at $96 \mathrm{~h}$. LTP7 expression was higher than the control from $48 \mathrm{~h}$ for both genotypes. However, the saline-tolerant genotype showed higher expression at $96 \mathrm{~h}$ (13.01) compared to the saline-sensitive genotype (8.04). The other genes formed a similar grouping trend based on the RQ values, showing slightly different RQ values over time of stress exposure and between genotypes (Figure 4A and B). 

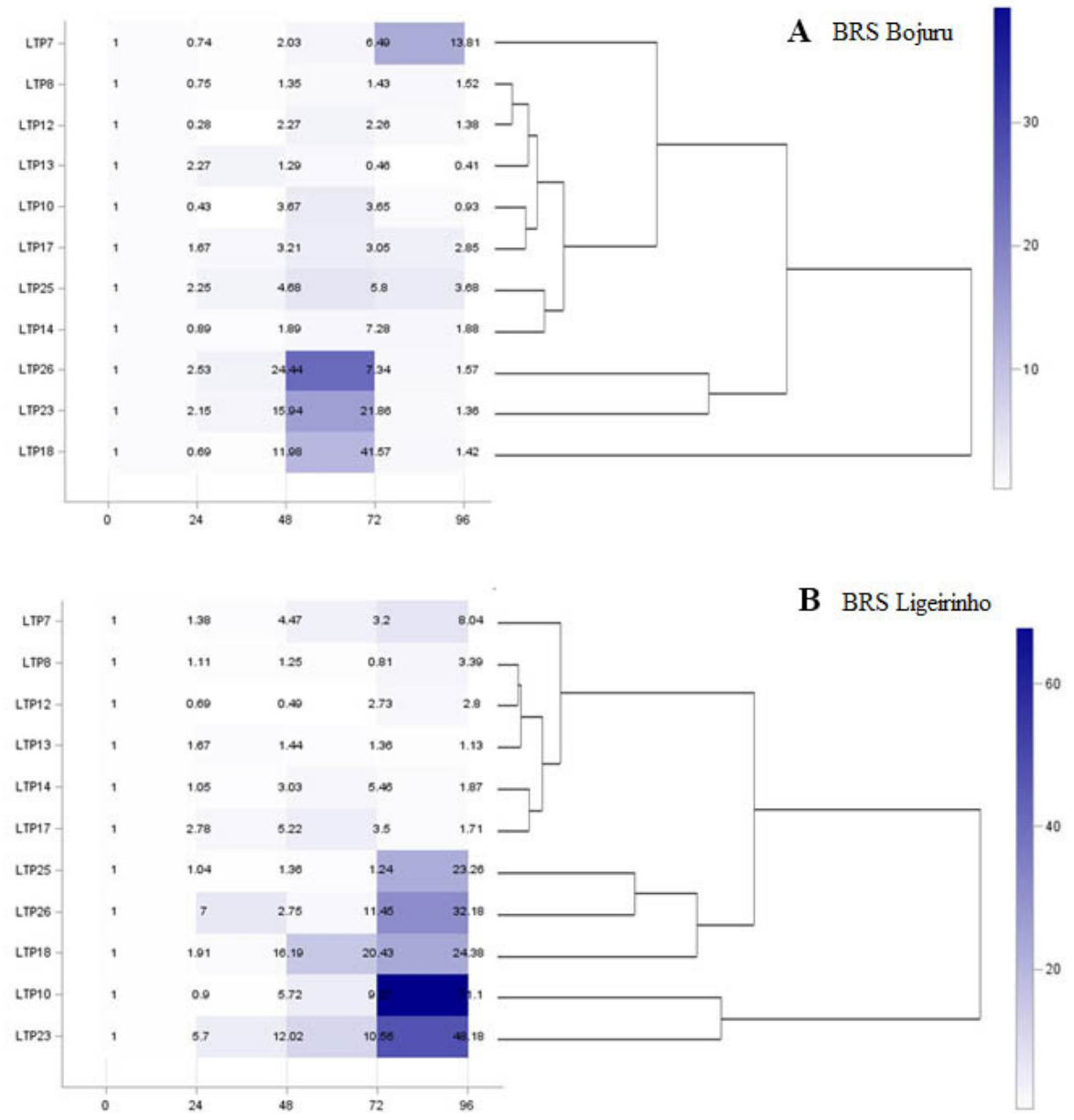

Figure 4. Dendrograms and heatmaps resulting from the grouping analysis of LTP genes based on the relative quantification (RQ) values for the genotypes BRS Bojuru (A) and BRS Ligeirinho (B).

\section{DISCUSSION}

The increasingly frequent occurrence of saline irrigation water has become a primary problem in the production of irrigated rice (Zhang, 2007). Because plants are sessile, they have developed a set of mechanisms that allow them to respond and adapt to biotic and abiotic stress conditions. Understanding these mechanisms and identifying genes related to the response to salinity is essential for identifying the metabolic pathways involved in the defense processes and, consequently, for developing molecular strategies to select rice plants that are more tolerant to this condition.

We examined differences in the expression of 11 genes in the LTP 1 family in 2 rice genotypes with contrasting responses to saline stress. Differentially expressed genes were identified between the treatments and/or between genotypes. Of the genes identified as be- 
ing differentially expressed at $96 \mathrm{~h}$ of stress, LTP10 showed a high expression value that was 70 -fold higher in the BRS Ligeirinho cultivar compared to the control treatment. In the BRS Bojuru cultivar, this same gene maintained a minimal expression pattern throughout the exposure to saline stress and is therefore a possible target molecular marker to identify genotypes sensitive to salinity.

The expression responses of the same gene under stress conditions can vary widely as a function of developmental stage, tissue or organ, type and intensity of stress, and genotype. Tapia et al. (2013) observed that expression of the LTP10 gene was induced in the leaves and stems of Lotus japonicus subjected to drought stress; however, its expression was repressed in the roots. Wang et al. (2009) examined the expression of the genes Th-LTP10, Th-LTP2, and Th-LTP3 of Tamarix hispida, and found that the expression of these genes was repressed by $\mathrm{NaCl}$ but induced by $\mathrm{NaHCO}_{3}$.

The LTP26, LTP23, and LTP 18 genes showed increased expression in both the salinesensitive and saline-tolerant genotypes; however, expression levels and response times differed between the genotypes. In the saline-tolerant genotype, these genes were activated after $48 \mathrm{~h}$ of stress, decreasing to values close to control values at $96 \mathrm{~h}$; this observation was in contrast to that of the saline-sensitive genotype, in which LTP26, LTP23, and LTP18 expression was increased with increasing stress time. This suggests that both plants use these genes in the acclimatization process.

The LTP8 and LTP13 genes showed the lowest induction by saline stress in the 2 genotypes, with a positive correlation in expression between them. Similar results were also obtained by Tapia et al. (2013), who analyzed the expression of the $L j L T P 8$ and $L j L T P 9$ genes in the stems, leaves, and roots of $L$. japonicus under drought stress. $L j L T P 8$ showed an unrepresentative increase in expression, while the expression of $L j L T P 9$ remained at low transcription levels. Thus, these genes may not be useful for identifying genotypes that are tolerant or sensitive to salinity.

The data obtained in this study agree with those of Wang et al. (2012), who evaluated the expression of different $L T P$ loci in the rice genome in plants irrigated with $250 \mathrm{mM}$ $\mathrm{NaCl}$ and observed that some loci showed different responses to salt. These authors observed increased expression of the genes Os11g24070, Os04g33920, and Os05g06780 in a 12-h exposure period to stress and that the genes Os12g02340, Os11g02400, and Os11g02369 showed no alterations in expression levels.

The involvement of LTP genes in the response to saline stress was also observed in other species such as barley (Hordeum vulgare L.). Federico et al. (2005) studied the expression of the LTP6 gene in barley plants under saline stress, cold stress, and ABA application and observed that increased expression of this gene was most significant under saline stress, reaching values of 3.3- vs 2.3-fold of the control levels after treatment with ABA and 1.6-fold the control under cold stress treatment.

Thus, our results and those of previous studies reinforce the importance of studies aimed at genetic families, as isoforms of genes belonging to the same family of proteins show different responses according to the environmental condition, development stage, genotype, or tissue evaluated.

In summary, the $L T P 7$ gene showed higher expression levels in the saline-tolerant genotype (BRS Bojuru), while LTP10 was more highly expressed in the saline-sensitive genotype. Further studies should be conducted to identify molecular markers for the selection of contrasting genotypes for saline stress. LTP26, LTP10, and LTP23 showed contrasting expression responses between the genotypes and were negatively correlated. 


\section{ACKNOWLEDGMENTS}

Research supported by the Brazilian funding agencies: Coordenação de Aperfeiçoamento de Pessoal de Nível Superior (CAPES), Conselho Nacional de Desenvolvimento Científico e Tecnológico (CNPq), and Fundação de Amparo à Pesquisa do Rio Grande do Sul (FAPERGS).

\section{Supplementary material}

\section{REFERENCES}

Abbas MK, Ali SA, Hasan HH and Ghal RH (2013). Salt tolerance study of six cultivars of rice (Oryza sativa L.) during germination and early seedling growth. J. Agr. Sci. 1: 250-259.

Boutrot F, Chantret N and Gautier MF (2008). Genome-wide analysis of the rice and Arabidopsis non-specific lipid transfer protein (nsLtp) gene families and identification of wheat nsLtp genes by EST data mining. BMC Genomics 9: 86.

Carvalho Ade O and Gomes VM (2007). Role of plant lipid transfer proteins in plant cell physiology-a concise review. Peptides 28: 1144-1153.

Choi AM, Lee SB, Cho SH, Hwang I, et al. (2008). Isolation and characterization of multiple abundant lipid transfer protein isoforms in developing sesame (Sesamum indicum L.) seeds. Plant Physiol. Biochem. 46: 127-139.

Djanaguiraman M, Ramadass R and Devi DD (2003). Effect of salt stress on germination and seedling growth in rice genotypes. Madras Agric. J. 9: 50-53.

Food and Agriculture Organization of the United Nations (FAO) (2008). Extent and Causes Salt-affected Soils in Participating Countries - Land and Plant nutrition management service. Available at [http://www.fao.org/ag/agl/agll/ spush/topic2.htm\#top]. Accessed April 7, 2013.

Food and Agriculture Organization of the United Nations (FAO) (2013). The state of food and agriculture. Available at [http://www.fao.org/.2013]. Accessed March 31, 2013.

Federico ML, Kaeppler HF and Skadsen RW (2005). The complex developmental expression of a novel stress-responsive barley Ltp gene is determined by a shortened promoter sequence. Plant Mol. Biol. 57: 35-51.

Gomes EE, Sagot C, Gaillard L, Laquitaine B, et al. (2003). Nonspecific lipid transfer protein genes expression in grape (Vitis sp.) cells in response to fungal elicitor treatments. Mol. Plant Microbe Interact. 16: 456-464.

Gonorazky AG, Regente MC and de la Canal L (2005). Stress induction and antimicrobial properties of a lipid transfer protein in germinating sunflower seeds. J. Plant Physiol. 162: 618-624.

Hoagland DR and Arnon DI (1938). The water culture method for growing plants without soil. University of California College of Agriculture, Berkeley.

Hollenbach B, Schreiber L, Hartung W and Dietz KJ (1997). Cadmium leads to stimulated expression of the lipid transfer protein genes in barley: implications for the involvement of lipid transfer proteins in wax assembly. Planta 203: 9-19.

Hong CY, Hsu YT, Tsai YC and Kao CH (2007). Expression of ASCORBATE PEROXIDASE 8 in roots of rice (Oryza sativa $\mathrm{L}$.) seedlings in response to $\mathrm{NaCl}$. J. Exp. Bot. 58: 3273-3283.

Hwang EW, Kim KA, Park SC, Jeong MJ, et al. (2005). Expression profiles of hot pepper (Capsicum annuum) genes under cold stress conditions. J. Biosci. 30: 657-667.

Jang CD, Kim S, Bu J, Kim S, et al. (2002). Isolation and characterization of lipid transfer protein (LTP) genes from a wheat-rye translocation line. Plant Cell Rep. 20: 961-966.

Karan R, DeLeon T, Biradar H and Subudhi PK (2012). Salt stress induced variation in DNA methylation pattern and its influence on gene expression in contrasting rice genotypes. PLoS One 6: e40203.

Kirubakaran SI, Begum SM, Ulaganathan K and Sakthivel N (2008). Characterization of a new antifungal lipid transfer protein from wheat. Plant Physiol. Biochem. 46: 918-927.

Liu KH and Lin TY (2003). Cloning and characterization of two novel lipid transfer protein I genes in Vigna radiate. DNA Seq. 14: 420-426.

Livak KJ and Schmittgen TD (2001). Analysis of relative gene expression data using real-time quantitative PCR and the $2^{-\Delta \Delta c t}$ Method. Methods 25: 402-408.

Mansour MMF, Salama KHA and Al-Mutawa MM (2003). Transport proteins and salt tolerance in plants. Plant Sci. 164: 891-900.

Mittler R (2002). Oxidative stress, antioxidants and stress tolerance. Trends Plant Sci. 7: 405-410.

Genetics and Molecular Research 14 (3): 8294-8305 (2015)

CFUNPEC-RP www.funpecrp.com.br 
Moraes GP, Benitez LC, do Amaral MN, Vighi IL, et al. (2015). Evaluation of reference genes for RT-qPCR studies in the leaves of rice seedlings under salt stress. Genet. Mol. Res. 14: 2384-2398.

Oshino TM, Abiko R, Saito E, Ichiishi M, et al. (2007). Premature progression of anther early developmental programs accompanied by comprehensive alterations in transcription during high-temperature injury in barley plants. Mol. Genet. Genomics 278: 31-42.

Pacios LF, Gómez-Casado C, Tordesillas L, Palacín A, et al. (2012). Computational study of ligand binding in lipid transfer proteins: structures, interfaces, and free energies of protein-lipid complexes. J. Comput. Chem. 33: 18311844.

Panda SK and Khan MHG (2009). Growth, oxidative damage and antioxidant responses in Greengram (Vigna radiata L.) under short-term salinity stress and its recovery. J Agron. Crop Sci. 195: 442-454.

Rasmussen R (2001) Quantification on the lightcycler. In: Rapid cycle real-time PCR, methods and applications (Meuer S, Wittwer C and Nakagawara K, eds.). Springer Press, Heidelberg, 1: 21-34.

Tapia G, Morales-Quintana L, Parra C, Berbel A, et al. (2013). Study of nsLTPs in Lotus japonicus genome reveal a specific epidermal cell member (LjLTP10) regulated by drought stress in aerial organs with a putative role in cutin formation. Plant Mol. Biol. 82: 485-501.

Vignols F, Wigger M, García-Garrido JM, Grellet F, et al. (1997). Rice lipid transfer protein (LTP) genes belong to a complex multigene family and are differentially regulated. Gene 195: 177-186.

Wang C, Yang C, Gao C and Wang Y (2009). Cloning and expression analysis of 14 lipid transfer protein genes from Tamarix hispida responding to different abiotic stresses. Tree Physiol. 29: 1607-1619.

Wang NJ, Lee CC, Cheng CS, Lo WC, et al. (2012). Construction and analysis of a plant non-specific lipid transfer protein database (nsLTPDB). BMC Genomics 13 (Suppl 1): S9.

Wu G, Robertson AJ, Liu X, Zheng P, et al. (2004). A lipid transfer protein gene BG-14 is differentially regulated by abiotic stress, ABA, anisomycin, and sphingosine in bromegrass (Bromus inermis). J. Plant Physiol. 161: 449-458.

Yeats TH and Rose JK (2007). The biochemistry and biology of extracellular plant lipid-transfer proteins (LTPs). Protein Sci. 17: 191-198.

Yi S, Park M, Kim J and Choi ID (2009). AlLTPs from Allium species represent a novel class of lipid transfer proteins that are localized in endomembrane compartments. Plant Biotechnol. Rep. 3: 213-223.

Yubero-Serrano EM, Moyano E, Medina-Escobar N, Munõz-Blanco J, et al. (2003). Identification of a strawberry gene encoding a non-specific lipid transfer protein that responds to ABA, wounding and cold stress. J. Exp. Bot. 54: 1865-1877.

Zhang Q (2007). Strategies for developing green super rice. Proc. Natl. Acad. Sci. U. S. A. 104: 16402-16409.

Zhu JK (2001). Plant salt tolerance. Trends Plant Sci. 6: 66-71. 